\title{
Inovação de significado na moda: a influência dos processos criativos e do propósito de marca
}

Meaning innovation in fashion: the influence of creative processes and brand purpose

DA LUZ, Deise; Mestranda em Design Estratégico; Unisinos - Universidade do Vale do Rio dos Sinos deiseluzz@gmail.com

BORBA, Gustavo; Pós Doutor na Escola de Educação do Boston College; Unisinos - Universidade do Vale do Rio dos Sinos

gborba@unisinos.br

FREIRE, Karine; Doutora em Design; Unisinos - Universidade do Vale do Rio dos Sinos

kmfreire@unisinos.br

\section{Resumo}

O presente artigo analisou como a inovação de significado, por meio do design, pode ser relevante para a descontinuidade sistêmica no sistema de produção e consumo da moda, ligada aos princípios do slow fashion. A escolha metodológica pelo estudo de caso nos proporciona reflexões sobre como empreendedores criativos da moda podem, a partir de seus propósitos, criar marcas que apresentam modos de ressignificar o consumo de moda. A NUZ, marca gaúcha estudada, preza por modelagens funcionais e atemporais, que pensou seu produto exemplar, o NUZ, a partir das possibilidades de transformação com uma modelagem que possibilita, no mínimo, oito usos diferentes. $O$ estudo mostra como a inovação de significado está presente ao longo do processo de criação e desenvolvimento da peça e como o propósito da marca influência na mudança de comportamento rumo à ressignificação do consumo de roupas.

Palavras Chave: Inovação de Significado; Processos Criativos; Propósito de Marca.

\begin{abstract}
This article analyzes, through design, how the innovation of meaning can be relevant for the systemic discontinuity related to the fashion production and consumption, linked to the slow fashion principles. The methodological choice of case study, provides reflections on how creative entrepreneurs can, by their own purposes, create brands that show ways of re-signifying fashion consumption. The NUZ, a brand based in Rio Grande do Sul, values functional and timeless modeling, which thought its main product, the NUZ, from the possibilities of transformation in at least in eight different models. The study shows how the innovation of meaning is present throughout the process of piece creation and its development, and how the brand purpose influences the behavior change towards the re-signification of clothes consumption.
\end{abstract}

Keywords: Innovation of Meaning, Innovation Process; Brand Purpose. 


\section{Introdução}

Por duas décadas, os estudos em design valorizaram os métodos estabelecidos a partir do human-centered design, praticados por empresas como IDEO e seu criador Tim Brow. Para BROW (2009), a complexidade dos problemas que os designers atuais enfrentam exige uma mudança de postura, em que a pergunta chave para um profissional passa a ser: porque devo projetar? E não mais: como devo projetar? Essa forma de pensar o design carrega muitas questões relacionadas às necessidades atuais do momento em que vivemos, colocando a disciplina à frente de soluções para problemas ambientais e sociais, e não apenas centrada na concepção estética e ergonômica de produtos. Essas necessidades exigem novas características advindas da cultura de design. Essa cultura, para Manzini (2015), é a base para a solução de problemas, em que especialistas de design entram em ação com suas habilidades de alimentar e apoiar processos, funcionando como atores sociais, e cultivando a cultura de design para que todos, especialistas ou não, possam trabalhar como designers, encontrando, juntos, soluções para os problemas existentes. 0 caminho rumo à sustentabilidade ocorrerá através do aprendizado social, promovendo descontinuidades sistêmicas. "Essa transformação atingirá todo o sistema sóciotécnico no qual vivemos e também as várias escalas do tempo e do espaço, iniciando localmente e progredindo para descontinuidades radicais em escala global" (MANZINI, 2008 p. 19). Nesse sentido, desloca-se a atenção do human-centered design para uma visão ecossistêmica, em que não há centralidade em soluções de problemas humanos e sim a colaboração de todos, melhorando o bem-estar social da humanidade.

Para Verganti (2017), a partir da disseminação da cultura de design ocorrida ao longo dos anos, observa-se um alto índice de novas ideias geradas para a solução de problemas humanos, mas qual o real significado dessas novas ideias? Elas exercem potencial de inovações radicais, com capacidade para modificar sistemas estabelecidos e realmente contribuir com as questões emergentes enfrentadas pela sociedade e pelo planeta? Verganti (2017) aponta que uma verdadeira inovação de significado acontece quando a tecnologia e o propósito convergem, gerando algo novo e realmente impactante para a sociedade. Baseado no princípio da crítica, Verganti (2017) sugere que os designers que operam nos processos de inovações de significados partem de uma ideia "de dentro para fora", para depois expor essa ideia para seus pares, iniciando um momento de troca estabelecido por uma relação de confiança, incentivando à crítica para que a ideia seja evoluída ainda em fase de concepção.

É um momento de mudanças, fértil para o afloramento de novos propósitos, mais conscientes e mais sustentáveis. No Brasil, o design de moda parece estar em ascendência e novas marcas surgem a cada dia. Porém, qual o propósito dessas novas marcas? Qual o processo que faz dos designers idealizadores de inovações disruptivas, capazes de subverter a ordem e contribuir com a descontinuidade sistêmica relacionada à indústria de vestuário? Com o intuito de contribuir com as respostas para essas perguntas, este artigo apresenta um estudo de caso da NUZ, marca de moda gaúcha, que tem no seu DNA a arte e a funcionalidade traduzidas em uma peça de roupa versátil e atemporal, que pode ser usada de, no mínimo, oito formas diferentes e que reflete a inovação de significado (VERGANTI, 2017) a partir da essência de sua estilista. Iremos explorar o processo de projeto experimentado pela marca e suas semelhanças com o processo de inovação de significado, bem como o desenvolvimento do propósito e as indicações de contribuição para o movimento slow fashion. 


\section{Processo de Inovação de Significado}

No design, a inovação está relacionada com os efeitos de sentido que um sistema produtoserviço produz, sendo, o processo de projeto, o caminho para a estratégia de geração desses sentidos (ZURLO, 2010). Os processos de projeto conhecidos e disseminados pelo design nas últimas décadas esteve baseado no desenvolvimento de ideias colaborativas, por meio de ferramentas que são capazes de habilitar o desenvolvimento e a tangibilização das abstrações dos participantes. Nessa lógica de colaboração, são considerados especialistas e não especialistas, designers ou não, que tem potencial de contribuição para um projeto. É uma atividade transdisciplinar que envolve níveis diferentes de profissionais, compreendendo, acima de tudo, ao longo do processo de criação, a participação do usuário. Esse processo é também conhecido como co-design. (SANDERS; STAPPERS, 2007). Meroni (2008) compreende como co-design o ato de designers e sociedade trabalharem juntos na geração de cenários para a inovação. Inúmeros projetos de sucesso apresentados por escritórios de design como a IDEO e por pesquisadores como Manzini consideram o usuário em todo ou em parte do processo, demonstrando a efetividade deste modo de fazer design: consciente, humano e colaborativo. Segundo Mauri (1996), os saberes e as competências se fazem, no projeto da estratégia, experiências de transdisciplinaridade, de cruzamento de informações e de diferentes olhares dos sujeitos que intencionalmente sincronizam em tempo real seus pensamentos e aprendizagens, tornando o projeto uma construção contínua de um debate coletivo e interativo. Através dessa colaboração, todos os atores podem gerar demandas, perceber oportunidades, aprofundar posições, comunicar e avaliar decisões e responsabilidades permanentes, como respostas à incerteza e ao caos.

Com tudo, podemos observar a existência de dois tipos de inovações: as inovações de soluções e as inovações de significado (VERGANTI, 2017). As inovações baseadas em soluções são pautadas por problemas pré-determinados, que tenham como objetivo melhorar a vida das pessoas, considerando a colaboração como pilar para a geração de ideias. Essas inovações são, normalmente, do tipo incremental. Um exemplo de inovação de solução do tipo incremental no mercado de moda pode ser o desenvolvimento de um tingimento menos poluente. Esse tingimento, que pode ser aplicado em diferentes tipos de roupas, é uma inovação tecnológica, mas que pode não gerar um novo valor para a sociedade, logo, não ganhar a força que precisa para transformar a cadeia da moda. Diferentemente das inovações baseadas em soluções, as inovações de significado subvertem a lógica das criações, são inovações que transcendem as tecnologias e passam a operar na entrega de novos valores (VERGANTI, 2017) para todos os níveis de envolvidos: usuários, organizações, sociedade e ecossistema (OUDEN, 2012). O desafio está em entender o que é valor para essas pessoas, que vivem em um mundo em constante mudança, trocando de ideias e experimentando diferentes emoções com tamanha fluidez, fazendo com que, muitas vezes, um produto pautado por evoluções tecnológicas, que apenas preveem o melhoramento de soluções já existentes, seja obsoleto desde o seu lançamento. Dessa forma, para ser uma inovação radical, é necessário dar novo sentido às ideias e propor novas interpretações (VERGANTI, 2017).

$\mathrm{Na}$ contramão dos princípios estabelecidos nas inovações de soluções, que consideram os movimentos de "fora para dentro" (observam como os usuários utilizam produtos e serviços primeiro, para depois projetar) e a geração de muitas ideias para que delas surja uma realmente boa, as inovações de significado acontecem de "dentro para fora" e são baseadas no princípio da 
crítica. Primeiro, o criador intui uma bem feitoria para a humanidade, muito embasada por hipóteses que surgem de suas vivências e de como essa inovação será benéfica para a sua própria vida e para a vida das pessoas próximas (ISAACSON, 2011; VERGANTI, 2017), depois, essa ideia é exposta para os seus pares, com quem, geralmente, o criador possui alto grau de envolvimento profissional e de confiança. Na troca entre os pares é que acontece a crítica, sendo ela importante para o processo de projeto, pois abre espaço para a discussão, gerando evolução em relação à ideia inicial. Diferentemente do processo utilizado em inovações de soluções, em que a crítica de uma ideia é suprimida pela cultura de gerar muitos "insights" primeiro, para depois cortar, fazendo com que os participantes sintam-se confiantes para inferir sugestões, nas inovações de significado a crítica é um princípio bem-vindo em todas as etapas do projeto. É importante reforçar que a palavra "crítica" nem sempre significa algo negativo, podendo ser um processo de constatações e validações positivas em relação ao objeto criticado. "A maneira mais delicada de praticar a arte da crítica é trabalhando em pares. Os pares são dois indivíduos que previram direções semelhantes. Ao se desafiar, naturalmente, tenderão a aprofundar suas reflexões, sem matar suas visões" (VERGANTI, 2017).

Entendemos, então, que a crítica entre os pares é um processo de evolução e fortalecimento de ideias. Porém, mesmo em inovações de significado, existem validações inerentes ao processo de projeto. Para isso, após a ideação individual e a crítica entre pares, chega o momento de dividir as hipóteses com grupos maiores. Esses grupos podem ser, inicialmente, funcionários de uma organização e, posteriormente, estrangeiros, ou seja, especialistas vindos de outras organizações. Nos estágios mais avançados do processo de projeto a ideia é também aberta para os usuários, sendo testada e validade por eles. Podemos, contudo, perceber, que a participação das demais pessoas (grupos de especialistas e usuários) não é relacionada ao processo de ideação, e sim ao processo de validação ou refutação de ideias já consolidadas entre pares. Essa participação contribui para a inovação de significado, pois os participantes trazem inúmeras perguntas, fazendo com que a ideia seja testada e evoluída (VERGANTI, 2017). O desenvolvimento e sucesso de uma inovação de significado também depende do engajamento dessas outras pessoas, que participam das etapas de testes e implementações, motivando seus criadores em momentos de incertezas e no enfrentamento de dificuldades técnicas. Essas pessoas são consideradas facilitadoras do processo de projeto, contribuindo, principalmente, com a defesa da causa, trazendo energia e entusiasmo para levar a ideia à diante, cenário que demonstra a importância da gestão de uma boa equipe ou grupo que seja entusiasmado com a marca ou, no caso, com a inovação pretendida (TIDD, 2008). A participação de especialistas e usuários nas inovações de significado parece estar relacionada com a prática de testar produtos e serviços, semelhante à prototipação, comumente utilizada nos processo de inovação de soluções. Nesse sentido, é possível perceber que as semelhanças e diferenças se fazem presentes, constituindo os dois modos de inovações apresentados, o que não invalida nenhum deles, sendo ambos eficazes, porém, com diferentes vertentes e objetivos.

Para Verganti (2017), uma inovação de significado tem ligação com a criação de novas tecnologias. Essa constatação está ilustrada no gráfico abaixo (figura 1), em que o primeiro quadrante representa a inovação radical, baseada em novos significados e novas tecnologias. As inovações de significado estão relacionadas com o porquê das coisas, propondo uma nova e mais significativa razão para que as pessoas utilizem produtos e serviços, podendo ser entendida como a ideação de um novo caminho a ser percebido e percorrido. Parece ser um formato coerente com o momento atual do mundo, considerando a indústria da moda, que precisa ser repensada e 
ressignificada em decorrência dos problemas ambientais e sociais sabidamente existentes e enraizados, em função da cultura de consumo estabelecida pós-revolução industrial.

Figura 1 - Inovação de Significado

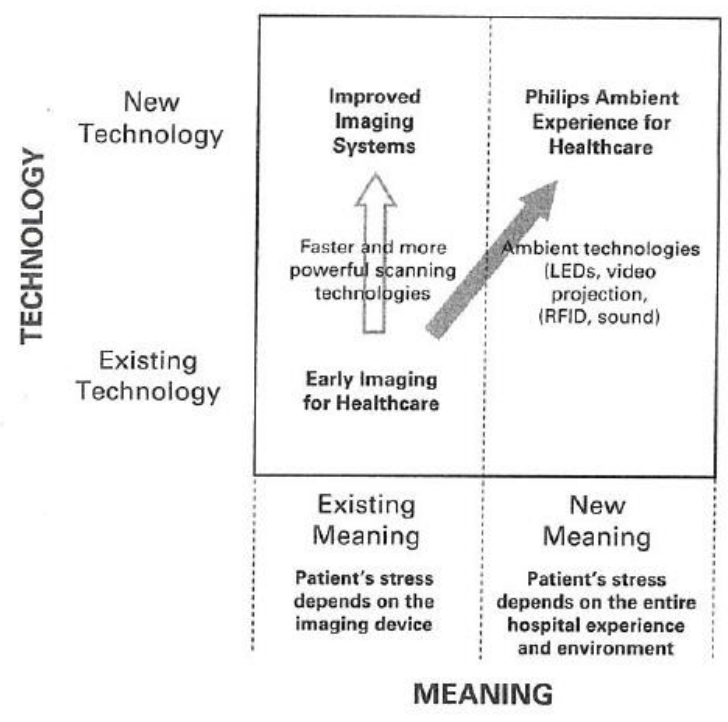

Fonte: (VERGANTI, 2017; p.59)

Inovações baseadas apenas em novas tecnologias, que não modificam os significados já existentes, normalmente são percebidas como inovações incrementais, ou seja, inovações de soluções, que evoluem tecnologicamente um produto ou serviço, mas, não necessariamente motivam uma mudança de comportamento. Outro exemplo de inovação tecnológica na indústria da moda são as roupas inteligentes, muito conhecidas no ramo de esportes em função de suas tecnologias relacionados à diminuição do suor melhorar a performance dos atletas. Porém, a inovação tecnológica inserida nas roupas não soluciona os problemas gerados ao meio ambiente, pois não incentiva o consumo consciente. Para serem consideradas inovações radicais, dentro da lógica apresentada por Verganti (2017), é preciso que novas tecnologias e novos significados estejam presentes. É também importante elucidar que parte do processo de inovação depende das redes estabelecidas entre as organizações, isto é, considerando que dificilmente uma única empresa ou criativo terá todo o conhecimento necessário para a produção e comercialização de uma inovação, são relevantes as trocas estabelecidas com outras organizações, sejam eles públicas ou privadas, através de laços fortes ou fracos, que possibilitem o intercâmbio de conhecimentos e informações (POWELL E GRODAL, 2007).

Esse estudo trata da inovação relacionada ao segmento de moda e a sua contribuição para a inserção do slow fashion na vida das pessoas. A inovação da marca NUZ está baseada no desenvolvimento tecnológico de tecidos e modelagens, bem como no propósito da marca e no significado que ela transmite, configurando-se um exemplo de inovação de significado. No capítulo seguinte exploraremos a importância do propósito atrelado às marcas inovadoras e sua contribuição rumo a inovações radicais. 


\section{Propósito de Marca como Instrumento de Inovação}

Grandes marcas constróem seus verdadeiros propósitos a partir de tradições morais enraizadas que podem, de acordo com Mourkogiannis (2006), ser explicadas a partir de quatro dos maiores filósofos da humanidade: Soren Kierkegaard, Aristóteles, David Hume e Friedrich Nietzsche. As ideias mais eficazes, atualmente, que compõem as tradições capazes de gerar propósitos sólidos são a descoberta, a excelência, o altruísmo e o heroísmo. Estudos demonstram que as organizações que seguem um ou mais desses quatro propósitos possuem mais chances de serem imunes ao tempo, pois constroem direções baseadas em fortes alicerces humanos, perdurando ao longo dos anos.

Partindo da visão articulada por Kierkegaard, o princípio da descoberta está baseado na ideia de que os seres humanos são livres, representando a moral de ter a conviç̧ão de fazer algo novo e seguir com a inovação ao longo da caminhada. O líder de uma organização orientada pela descoberta nunca pode descansar, está sempre em busca de desafios e avanços que mantenham as criações e produções à frente dos demais. Esse princípio é bastante utilizado em áreas como medicina e pesquisas tecnológicas, sendo de extrema utilidade para a evolução da humanidade. A excelência, deriva da filosofia moral de Aristóteles, que diz que o propósito está enraizado na intuição de que o nosso papel na vida é desenvolver o bem supremo, estando ele ligado às realizações, florescimentos e sucessos humanos. Praticam o propósito da excelência empresas como a Apple, que prezam por fazer sempre o melhor possível. O altruísmo está relacionado com a importância que damos ao bem-estar dos outros, bem como sobre o nosso. É derivado do trabalho de David Hume em que a filosofia moral corresponde ao que muitas pessoas pensam sobre moralidade. Organizações altruístas existem com o objetivo de ajudar os outros, os animais e o meio ambiente. É o propósito que mais está conectado com as ações sociais e ambientais, trabalhando para reduzir as desigualdades e melhorar vidas em todo o mundo. Por fim, o princípio do heroísmo, que deriva do pensamento de Nietzsche, está relacionado com dominar os padrões de uma indústria e construir o seu próprio caminho, como o exemplo de Henry Ford, que, sozinho, transformou o segmento de automóveis, definindo padrões para todos os outros poderem seguir, diferentemente do princípio da descoberta, que tem como premissa a liberdade humana, sem a intenção de ditar regras ou definir métodos (MOURKOGIANNIS, 2006).

Um sentido claro de propósito pode ajudar as organizações a manterem seus focos. É comum histórias de empresas que nasceram de ideias altruístas, mas, perderam sua essência ao longo do tempo. O altruísmo ganhou bastante força nos últimos anos, em decorrência da preocupação mundial com causas sociais e ambientais, tornando-se um propósito bastante valorizado pelas novas gerações, que prezam pela moral e bons costumes das organizações com questões como a fome no mundo e a preservação ambiental. Porém, será que muitas empresas não estão apenas vestindo um rótulo altruísta? Será que ser fiel ao propósito original de uma ideia ou organização pode ser o caminho para envolvimentos mais reais e inovações para todo o ecossistema, mesmo que ele não siga o padrão contemporâneo de propósitos organizacionais, baseados em altruísmo? O verdadeiro MTP - Propósito Transformativo Massivo, que está bastante relacionado com as organizações exponenciais, tem como resultado mais importante a geração de um movimento cultural, ou seja, o MTP quando é inspirador, motiva que uma comunidade se forme espontaneamente, fazendo com que o propósito opere por conta própria, criando sua tribo e cultura. Um bom propósito deve responder a dois "porquês": Por que isso funciona? Por que a organização existe? ISMAIL (2014). Essas perguntas devem permear o dia a dia das organizações para que estejam sempre alinhadas com os seus propósitos. 


\section{Procedimentos Metodológicos}

Esse estudo caracteriza-se como uma pesquisa exploratória e de natureza qualitativa. Pesquisas exploratórias, geralmente, são realizadas quando o tema em questão é pouco explorado e existe dificuldade na formulação de hipóteses. Desta maneira, esse tipo de pesquisa visa proporcionar maior familiaridade com o problema, com o intuito de torná-lo mais explícito, envolvendo levantamento bibliográfico e análise de exemplos que auxiliam na compreensão do tema e dos objetivos do estudo. Sua finalidade é o aperfeiçoamento de ideias ou o desvendar de intuições e seu planejamento é bastante flexível, de modo que possibilite a consideração de diferentes aspectos relativos ao fato estudado. A pesquisa qualitativa trata-se de uma metodologia de pesquisa exploratória, não estruturada, baseada em pequenas amostras com o objetivo de proporcionar ideias e entendimentos do ambiente do problema. Permite que o pesquisador levante dados subjetivos e não tem a presunção de mensurar variáveis, mas de analisar, qualitativamente, de modo indutivo, todas as informações levantadas (GIL, 2009).

Como instrumento de planejamento de pesquisa e coleta de dados optou-se por estudo de caso único. Um estudo de caso pode ser adotado quando se "investiga um fenômeno contemporâneo, dentro do seu contexto de vida real, especialmente quando os limites entre o fenômeno e o contexto não estão claramente definidos" (YIN, 2003). Tratando-se do caso da NUZ e do fenômeno de inovação de significado observado dentro do contexto da moda, considerou-se pertinente aprofundar o entendimento sobre as características que definem a estilista da marca como idealizadora de novos significados capazes de gerar mudanças radicais na forma de vestir-se. Para tanto, como fonte de informação, realizou-se triangulação de dados: site e redes sociais da marca como instrumento de análises documentais; entrevista semiestruturada com a estilista Duda Cambeses realizada no dia 15 de Janeiro de 2018 com duração de duas horas, estando presentes a estilista e a pesquisadora no 18+ Café, situado na universidade UNISINOS; entrevistas semiestruturadas com dois consumidores do NUZ tendo sido realizadas por e-mail, seguindo o critério de conveniência; entrevistas espontâneas captadas no ateliê e em feiras que a marca participou nos últimos meses, em que, através de vídeos, as clientes expressam reações pelo produto. A triangulação de dados é a técnica que corrobora para a melhor reputação de pesquisas de estudos de caso (YIN, 2003). Para analisar os dados, optou-se pela análise de conteúdo do tipo categorial, em que são apresentadas as seguintes categorias baseadas nas etapas do processo de inovação de significado: "De dentro para fora", A crítica, Desenvolvimento Tecnológico e Propósito da marca. A função sistemática da análise de conteúdo ajuda a reinterpretar as mensagens e aumenta o grau de compreensão do pesquisador, indo além da leitura comum dos dados (MORAES, 1999).

\section{NUZ: um caso de inovação de significado baseado em propósito}

NUZ é a marca da estilista Duda Cambeses, criada em 2015 na cidade de Porto Alegre - RS. A marca possui o produto NUZ, que é desenvolvido e aperfeiçoado há quase 10 anos por sua criadora, sendo a principal peça da coleção contínua da NUZ. Nesse artigo, trataremos especificamente desse produto. O NUZ é uma peça atemporal e versátil, que pode ser vestido de, no mínimo, oito formas diferentes, sendo suéter, calça, vestido e saia, ao mesmo tempo. Nesse 
sentido, ao longo do presente estudo, discorreu-se sobre as categorias selecionadas com o objetivo de responder as perguntas relacionadas ao problema da sustentabilidade na moda, traçando um perfil de propósito e significado de marca capaz de contribuir com o movimento slow fashion.

\section{1 "De dentro para fora"}

A partir da análise de dados foi possível perceber que o processo de criação, tanto da marca quanto do produto NUZ, está intrinsecamente ligado à sua estilista, sendo a história de vida dela, desde a infância, forte motivadora da idealização do produto, que está transformando-se em uma inovação de significado capaz de subverter a lógica de pensar o vestir. Segundo Verganti (2017), a inovação de significado acontece "de dentro para fora", ou seja, parte da idealização de uma pessoa a partir de seus desejos e inspirações. A constatação de que o NUZ pode tratar-se de uma inovação de significado começou a partir da analise do vídeo que é apresentado logo na abertura do site, disponível no seguinte endereço: http://nuz.art.br/?route=pages/intro, e também compartilhada nas redes sociais da NUZ. Abaixo segue a transcrição de um trecho do material que explana sobre como a estilista e criadora desenvolveu a marca e o produto NUZ, quais foram as suas referências e inspirações. Logo após, a mesma essência é apresentada pela própria estilista, no dia 15 de Janeiro de 2018, no decorrer da entrevista semiestruturada. Complementando, seguem alguns trechos referentes às falas de possíveis clientes ao conhecerem o NUZ, captados no ateliê e em feiras de moda.

Eu tive uma infância muito fértil, criativamente falando. Eu sou filha de pai Gaúcho, que morou muitos anos na Alemanha, ele é fotógrafo. Minha mãe bailarina, Baiana, de origem Espanhola, e eles me levavam por muitas aventuras pelo Brasil a fora, o que trouxe uma sensação que vive em mim, de ser um pouco forasteira. Nuz, o nome da minha marca, tem a ver com essa natureza (NUZ.ART.BR, 2018).

[...] as minhas referências tem muito a ver com as minhas vivências. Principalmente desde a infância, porque foi um período em que eu tive uma liberdade muito diferente da maioria das crianças, porque eu viajei muito, conheci pessoas do Brasil inteiro, eu tive uma vivência múltipla [...] minha mãe é artista, o meu pai é fotógrafo, meu avô é fazendeiro. Na fazenda eu tinha liberdade de ir para onde eu quisesse, ficar até a hora que eu quisesse e eu acho que essa coisa, não só da natureza, do campo, mas da liberdade em si, do espaço, espaço pro movimento, pro pensamento, acho que esse é o meu grande diferencial enquanto ser humano, e eu tento traduzir isso para o NUZ. (CAMBESES, 2018).

[...] que incrível gente, é sensacional, você é um gênio, eu estou apaixonada. (VÍDEO ENTREVISTA, 2018).

[...] parabéns artista, estou de queixo caído com o seu talento. (VÍDEO ENTREVISTA, 2018).

\subsection{A crítica}

A crítica é uma etapa, considerada por Verganti (2017), muito rica para o processo de 
inovação de significado, pois, diferentemente dos processos baseados em inovações de soluções, que suprimem o momento de crítica por acreditar que ele pode prejudicar o processo de ideação, na inovação de significado ela é encorajadora e certificadora. No caso do NUZ, a estilista Duda Cambeses relata ter tido um processo não linear relacionado à crítica, tendo ela acontecido de forma natural ao longo dos 10 anos de desenvolvimento do produto. Críticas vindas principalmente de outras estilistas, que também sofrem com a solidão de um criativo e que foram pares de Duda em momentos de incertezas e de motivações sobre o produto.

[...] eu coloquei ele como um produto que existe porque uma amiga minha disse: esse produto tá pronto. Ela trabalhou junto comigo vários anos, é figurinista também e tal, a Mariba... Eu considero que ela foi a pessoa que me deu o toque de não me exigir tanto: tu já tens um produto, tu vai continuar evoluindo ele. Por que eu queria que fosse algodão orgânico, com tingimento vegetal, e ela disse: tu vai conseguir isso daqui alguns anos, agora, nesse momento, tu tens esse produto que tá excelente, que eu compraria agora. Daí eu digo: mas sem acabamento, cortado a fio. E ela disse: e daí? Tá lindo assim. No meu flipbook ela tá lá, entre as pessoas que participaram do processo. A Mariba com certeza foi a pessoa que me clareou a visão. (CAMBESES, 2018).

[...] eu não consigo trabalhar sem dividir as minhas ideias, sem ser ouvida por alguém, é uma questão até que vem sendo discutida ultimamente, eu não consigo mesmo ser produtiva na mesma medida se eu não tiver uma pessoa com quem dividir o meu olhar e isso eu vejo que não sou só eu, várias pessoas parecidas comigo, ou do mesmo segmento, ou de um tipo de pensamento criativo parecido, a Helen por exemplo. Então eu e a Helen, a gente se ajuda muito nesse sentido, por que a gente as vezes não tem essa segunda pessoa perto (CAMBESES, 2018).

\subsection{Desenvolvimento Tecnológico}

A inovação tecnológica, considerada por Verganti (2017) como necessária para a inovação de significado, também é um processo em constante desenvolvimento para o caso do NUZ. A tecnologia para o segmento de moda é bastante baseada na pesquisa e na evolução dos tecidos, processo que não acontece de forma tão rápida quanto nos demais setores. A principal preocupação atual em relação ao desenvolvimento tecnológico de roupas está vinculada à fabricação de tecidos sustentáveis, que não agridam o meio ambiente e os animais. O caminho de pesquisa ainda é longo, mas, mesmo minimamente, já podemos ver alguma movimentação nesse sentido. De qualquer forma, a curiosidade e a insistência da Duda fazem com que ela, desde 2008, procure soluções em termos de tecidos para o NUZ. Atualmente, a peça comercializada atende os desejos da estilista em relação ao cumprimento de algumas questões, como: caimento, versatilidade, gênero (a roupa é adaptada para homens e mulheres), tamanhos e etc. (Figura 2). A questão da sustentabilidade ainda é algo que pode evoluir, mas, em termos tecnológicos, a roupa também cumpre o seu papel de colaborar com o slow fashion, pois é feita com tecidos de qualidade e que durarão por um longo tempo com seus usuários.

[...] aí eu comecei a ir a feiras, em Paris, a Première Vision, principalmente na França foi onde eu fui a mais feiras atrás de matéria prima pra poder começar a testar. Eu não sabia ir numa feira, não sabia como atuar numa feira né, foi ali que eu comecei a aprender de que forma buscar um fornecedor, de que forma ser atendida sendo uma pequena empresa [...] o moletom virou um projeto na gaveta, por muito tempo, daí aparecia um tecido que eu achava que podia ser, eu fazia um teste, mas daí ficava pesado e caia não 
sei o quê, aí eu entrei numas que eu precisava fazer uma coisa que servisse em todos os tipos de corpos [...] eu queria uma modelagem que fosse simples de realizar, pra que a produção dela fosse barata, pra que pudesse ser um preço popular, pra que todas as pessoas pudessem ter nos seus guarda-roupas. Hoje em dia a realidade que eu trabalho é que a matéria prima é extremamente cara, é pesada, mas cumpre com várias das funções que eu me propus, então eu não considero esse um produto fechado, eu considero que ele ainda tem muito para evoluir. (CAMBESES, 2018).

O NUZ representa liberdade acima de tudo, na minha opinião. Quando uso me sinto moderno e sofisticado, pela versatilidade que ele representa, ainda que não faça uso das variadas formas. O conforto que ele proporciona, pela sua modelagem e qualidade do tecido, é incomparável. (CONSONI, 2018).

Figura 2 - Croquis do NUZ
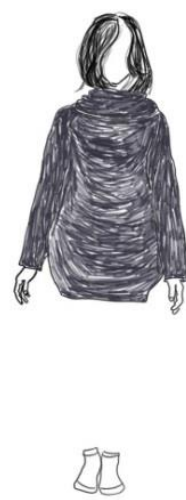
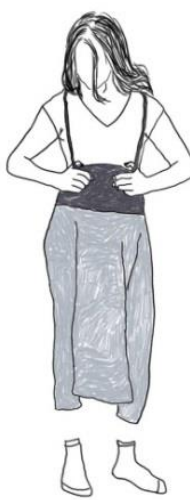
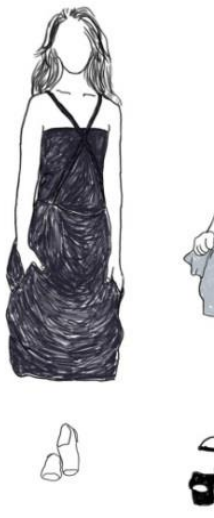
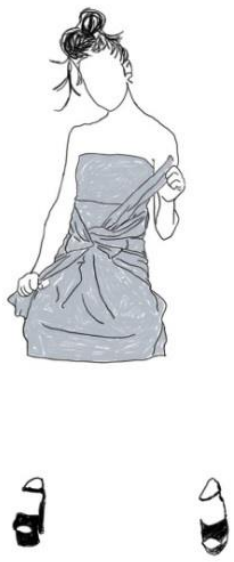

Fonte: https://www.facebook.com/nuzdemicouture/(2018)

\subsection{Propósito da marca}

O NUZ ainda está em construção, é uma peça com capacidade de transformação e adaptação que está em constante evolução. Essas características levam ao propósito da descoberta, que Mourkogiannis (2006) baseado no pensamento do filósofo Kierkegaard, define como o princípio que trata da liberdade humana, capaz de gerar inovação e carrega-la ao longo do tempo, sempre em busca de transformações e descobrimentos contínuos, que não se esgotam com o passar dos anos. Essas características ficam evidentes tanto na personalidade da estilista quanto na do produto, que nada mais é do que uma forma tangível de perceber a essência da criadora: camaleoa, mutante e livre. Seu propósito é fornecer liberdade para que as pessoas possam vestir-se e expressar-se de forma única, sem seguir padrões pré-estabelecidos pela indústria da moda. É um produto que possibilita, efetivamente, a customização da roupa, ressignificando a forma de pensar e consumir moda. Se for possível ter tantas peças em uma só, não é necessário comprar diversas roupas diferentes, basta que se tenha o NUZ. Esses e outros relatos aparecem traduzidos nos diferentes dados coletados, auxiliando na constatação de que o NUZ contribui para a descontinuidade sistêmica (MANZINI, 2008) na moda, fortalecendo e estimulando o movimento slow fashion (Figura 3). 
As peças que conformam a coleção contínua são atemporais, confortáveis e suas modelagens funcionais. Através de recursos estilísticos e acabamentos delicados confeccionados com técnicas de costura tradicional, permitimos a utilização de uma mesma peça de diferentes maneiras, incluindo o seu avesso. (NUZ.ART.BR, 2018).

[...] a primeira versão que eu fiz dele foi em 2007, 2006. A versão confeccionada. A ideia do que queria, do que surgiu, já tinha acontecido antes... quando eu já estava com o meu moletom, na minha cabeça ele tinha duas funções: saia e suéter. Daí eu fui, em 2008, numa viagem para Berlim, que eu queria levar só a malinha de mão, para poder trazer coisas de brechó da viagem, daí eu digo: vou levar só esse moletom, um jeans e uma camiseta e vou me virar. Só que daí no "eu vou me virar" eu vi que ele podia ser vestido, vestido, vestido, calça e daí foram nove dias que eu não repeti nenhum look variando a mesma peça. E daí eu digo, ah, se isso tiver mais elasticidade aqui pode facilitar tal coisa, ah, se isso não embolar aqui no meio pode ser assim. Então eu comecei a observar as características que eu precisava aplicar nele. (CAMBESES, 2018).

[...] naquele evento eu queria fazer algo diferente, e chamei algumas pessoas do próprio local para participar... [...] a minha mãe abriu o desfile fazendo uma coisa bem dramática, ela é espanhola, e isso deu a deixa pras outras pessoas fazerem alguma coisa com a roupa. Teve algumas pessoas que saíram chorando, emocionadas, porque nunca tinham feito nada em público ou nunca tinham, de verdade, se expressado nessa medida. Eu gosto de promover isso, as performances da NUZ tem esse viés de autoconhecimento, de sair da casquinha, isso é muito meu. (CAMBESES, 2018).

[...] vestido, moletom, não precisa de mais nada, só isso na vida. (VÍDEO ENTREVISTA, 2018).

[...] você vai pra uma viagenzinha de trabalho e você usa uma coisa só, é muito legal, adorei. (VÍDEO ENTREVISTA, 2018)

[...] eu criei uma flor com as mangas, isso aqui é a manga. Me acinturei, porque eu gosto de marcar a cintura, e fiz um estilo de vestido muito bonito. (VÍDEO ENTREVISTA, 2018).

Para mim representa unidade, equilíbrio. Funcionalidade, conforto e praticidade - coisas das quais ainda somos extremamente carentes enquanto sociedade moderna. Sinto totalidade, a liberdade de saber que poderei transitar entre diferentes mundos e necessidades sem grandes dificuldades, e que quando conto com ele conto menos com o tempo - pois acabo por ganhar mais dele - e isso realmente não tem preço (CERUTTI, 2018). 
Figura 3 - Roupa Transformável

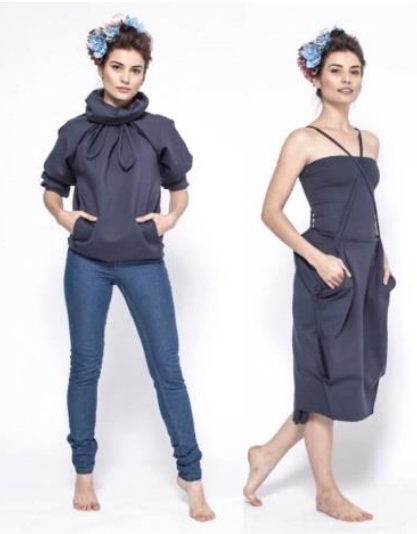

Fonte: https://www.facebook.com/nuzdemicouture/(2018)

Nesse sentido, é possível observar a relação da marca NUZ com a inovação de significado explanada por Verganti (2017) a partir da identificação de três fatores: 1 - A estilista é a protagonista da marca e da peça que existe em função de suas próprias inspirações e referências pessoais de vida, desde a infância, tratando-se de uma criação "de dentro para fora", daquelas criações que surpreendem as pessoas que recebem o produto como um presente idealizado pelo seu criador (ISAACSON, 2011; VERGANTI, 2017). 2 - O processo de produção do NUZ está de acordo com o processo de inovação de significado também pela posição da estilista com seus pares em relação à crítica ao produto. Os pares, geralmente, são pessoas de confiança do criativo, sendo, nesse caso, outras estilistas próximas e amigas de Duda. 3 - Existem inovações tecnológicas e de significado no produto NUZ, indicando que a peça pode ser classificada no primeiro quadrante da Figura 1 supracitada e que foi reinterpretada pela autora (Figura 4), apresentando os aspectos que classificam o NUZ como inovação de significado.

Figura 4 - Inovação de Significado NUZ

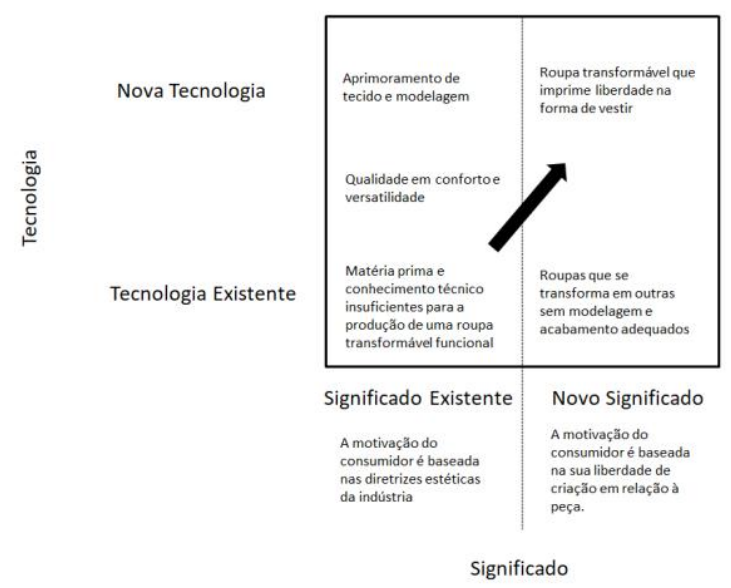

Fonte: Elaborado pela autora com base no quadro de Verganti (2017), apresentado na Figura 1 
O propósito da marca, que oferece para as pessoas liberdade e criatividade na hora do vestir, e que está alinhado com o propósito da descoberta de Mourkogiannis (2006), parece ser também um fator importante para a aproximação com a inovação de significado sugerida por Verganti (2017). Esse fator, aliado aos demais fatores demostrados na Figura 4, dá vida e personalidade ao produto NUZ, fazendo com que as pessoas possam tangibilizar a sua essência, primeiramente encantando-se com a sua performance e possibilidades de uso e, subsequentemente, refletindo sobre seu papel enquanto roupa que transforma a cultura da moda.

Os processos apresentados pela estilista da marca e observados ao longo dessa pesquisa não parecem ser lineares e pré-estabelecidos. Aconteceram intuitivamente ao longo dos 10 anos de estudos de Duda sobre o produto. A ideia criativa baseada na essência da estilista, a crítica entre os pares, o desenvolvimento tecnológico e o propósito da marca, são características que foram revelando-se ao longo dos contatos com a pesquisa documental sobre a marca e nas entrevistas com Duda, clientes e possíveis clientes. A descoberta do caso é que os processos criativos realizados pela NUZ, capazes de gerar inovações de significado, estão alinhados com a proposta de Verganti (2017): se incorporados aos momentos de ideação e desenvolvimento de produto, a valorização das ideias "de dentro para fora" vindas de estilistas e o processo de crítica entre pares, alinhados com os propósitos de cada marca, podem gerar e validar ideias disruptivas, como o NUZ. A partir dessas elucidações, pretende-se formalizar os processos de inovação de significado da marca NUZ para que sirvam de inspiração para outros criativos e que possam contribuir com produtos inovadores em prol da descontinuidade sistêmica na moda, aqui também tratada como slow fashion.

\section{Considerações Finais}

Os processos de design evoluíram ao longo dos anos, muito pautados pela necessidade de comportar a complexidade advinda dos problemas contemporâneos experimentados pela sociedade e pelo planeta. Ao longo das últimas duas décadas, empresas de design e pesquisadores desenvolveram teorias e técnicas e aplicaram em diferentes estudos de caso e experimentos. Porém, Verganti (2017) faz um paralelo entre os processos de design baseados em inovações de soluções (incrementais) e inovações de significado (possivelmente radicais). Para o autor, as inovações radicais são inovações que traçam uma nova direção a ser seguida, tratando-se, geralmente, de algo que as pessoas não estavam esperando. Essas inovações, quando alinhadas com propósitos claros estabelecidos por uma organização, podem subverter a lógica de consumo e criar uma nova cultura sobre determinado produto ou serviço. Diferentemente do processo experimentado nas inovações de solução, em que a crítica é suprimida pela prática de gerar ideias, nas inovações de significado ela é benéfica, pois valida a ideia que sai da cabeça de seu criador, sendo essa a mais importante defesa de Verganti (2017) em relação às inovações de significado: ideias que surgem de "dentro para fora", que são concebidas por uma pessoa, por um gênio criativo. Elas estão relacionadas com as referências de vida e necessidades de seu criador e, quando são validadas por pares e depois por grupos maiores, alimentadas por um propósito, tem o potencial de ganhar o mundo.

A partir do estudo apresentando, considera-se que a NUZ possa ser uma marca de 
inovação de significado, sendo o seu principal produto, o NUZ, uma roupa transformável, que pode ser usada de, no mínimo, oito formas diferentes, sendo essa peça o objeto de estudo do presente artigo. Ao longo do estudo de caso, que contou com a triangulação como método de coleta de dados, foi possível perceber as evidências de que Duda Campeses, a estilista e criadora da marca, é a gênia criativa por trás de uma peça única, que pode revolucionar a forma de pensar a moda, contribuindo para o movimento slow fashion. Ainda é longo o caminho até a confecção de um NUZ que seja feito de material orgânico e com um preço justo para que possa ser usado por todas as pessoas, mas, o propósito da criadora, de trazer liberdade ao vestir-se com moda ética e sustentável, segue sendo percorrido. Esse propósito, segundo Mourkogiannis (2006), pode ser comparado com o princípio da descoberta, que prevê a liberdade humana de estar em constante evolução e transformação. Essa essência, que tem muito da sua criadora, é transmitida para o NUZ, fazendo com que o vestir-se se torne uma arte para as pessoas, que podem modelar como quiserem a sua própria roupa de acordo com seus gostos e vontades, co-criando, junto com a estilista, um NUZ para si.

Como recomendação para estudos futuros, sugere-se investigar como o processo de design, considerando o NUZ uma peça de design aberto, pode ser também colaborativo. Essa indicação parte de uma afirmação de Duda Cambeses sobre seu interesse em participar de ações e grupos com vieses de inovação, sendo ela já integrante do Ecossistema de Moda Sustentável do Rio Grande do Sul, afiliado à rede DESIS (Design de Sistemas para a Inovação Social e Sustentabilidade) presidida por Ezio Manzini, que possui laboratórios colaborativos por todo mundo, inclusive no Brasil. Em qual momento o processo ecossistêmico de design pode ser útil na evolução e disseminação do NUZ ou para a transmissão de conhecimento para que outras marcar produzam peças tão inspiradoras quanto essa? Além dessas indicações, também pode ser realizada uma entrevista em profundidade com outros consumidores da marca a fim de entender as suas motivações e críticas em relação ao produto. Junto com o NUZ, esse estudo pretende evoluir e gerar novos conhecimentos para a área do design, principalmente em relação aos processos de design contemporâneos.

\section{Referências}

BROWN, Tim. Change by Design: How Design Thinking Transforms Organizations and Inspires Innovation. Harper Business; First Edition, 2009.

GIL, Antônio. Como Elaborar Projetos de Pesquisa. São Paulo, Atlas, 2009.

ISMAIL, S. Exponential Organizations: Why new organizations are ten times better, faster, and cheaper than yours (and what to do about it), Diversion Books, 2014.

ISSACSON, W. Steve Jobs, Simon e Schuster, 2011.

MANZINI, E. Design para a inovação social e sustentabilidade: comunidades criativas, organizações colaborativas e novas redes projetuais. Rio de Janeiro: E-papers, 2008.

MANZINI, E. Design, When Everybody Designs. An Introduction to Design for Social Innovation. Cambridge, MA: MIT Press, 2015.

MERONI, A. Strategic design: where are we now? Reflection around the foundations of a recent 
discipline. Strategic Design Research Journal, v.1, n.1, Dec 1, p.31-38. 2008.

MAURI, Francesco. Progettare Progettando Strategia. Milano: Ed. Dunod, 1996.

MORAES, Roque. Análise de conteúdo. Revista Educação, Porto Alegre, v. 22, n. 37, p. 7-32, 1999.

MOURKOGIANNIS, N. Purpose: The Starting Point of Great Companies, New York: Palgrave Macmillan, 2006.

NUZ.ART.BR. Site da marca. Disponível em: http://nuz.art.br/?route=pages/intro. Acesso em 15 de Janeiro de 2018.

OUDEN, Elke den. Innovation Design: Creating value for people, organizations and society. New York: Springer, 2012.

POWELL, W; Grodal, S. Networks Of Innovatores. In: The Oxford handbook of innovation. New York: Oxford, 2007. p. 656.

SANDERS, Elizabeth B-N; STAPPERS, Pieter Jan. Co-creation and the new landscapes of design. CoDesign, v.4, n.1, p-5-18, mar. 2008. Disponível em: <http://www.tandfonline.com/doi/abs/10.1080/15710880701875068>. Acesso em 16 de Julho de 2017

TIDD, J.; PAVITT, K., BESSANT, J. Gestão da Inovação. Porto Alegre: Bookman, 2008.

VERGANTI, Roberto. Overcrowded: Designing Meaningful Products in a World Awash with Ideas, London: The MIT Press, 2017.

YIN, Robert K. Estudo de caso: planejamento e métodos / Robert K. Yin; trad. Daniel Grassi - 2.ed. -Porto Alegre : Bookman, 2003.

ZURLO, F. Design Strategico. In: XXI Secolo, vol. IV, Gli spazi e le arti. Roma: Enciclopedia Treccani, 2010.

\section{ENTREVISTADOS:}

CAMBESES, D. Duda Cambeses: depoimento [jan. 2018] Entrevistadora: Deise da Luz. Porto Alegre: Unisinos. 1 arquivo em áudio no formato $\mathrm{mp} 4$. Entrevista concedida a pesquisadora para o artigo.

CONSONI, L. Leandro Consoni: depoimento [fev. 2018] Entrevistadora: Deise da Luz. Porto Alegre. Enviado por correio eletrônico. Entrevista concedida a pesquisadora para o artigo.

CERUTTI, D. Duanne Cerutti: depoimento [fev. 2018] Entrevistadora: Deise da Luz. Porto Alegre. Enviado por correio eletrônico. Entrevista concedida a pesquisadora para o artigo.

VÍDEO ENTREVISTA. Entrevista espontânea capturada através de vídeo gravado em feiras e no ateliê da marca. Disponível em: https://drive.google.com/drive/u/0/folders/1nK8ufHxsBvm4rCkuU96RIIXJuQBGWI92. Janeiro, 2018. 